УДК 316.74

22.00.00 Социологические науки

ПРЕДМЕТ «СОЦИОЛОГИЯ И КУЛЬТУРО-
ЛОГИЯ» В АСПЕКТЕ ИНТЕГРАЦИИ СО-
ЦИОГУМАНИАРНОГО ЗНАНИЯ: ТЕОРЕ-
ТИКО-МЕТОДОЛОГИЧЕСКИЙ ПОДХОД

Волкова Полина Станиславовна

д.филос.н., профессор

Передерий Вероника Анатольевна

к.с.н., доцент

РИНЦ SPIN -код 3806-2473

Кубанский государственный аграрный

университет имени И.Т. Трубилина, г.Краснодар, Россия

e-mail: sociolog@kubsau.ru

Статья посвящена методологии исследования новой для Кубанского государственного аграрного университета им. И.Т. Трубилина учебной дисциплины «Социология и культурология». Описаны конкретные задачи, которые ставятся перед профессорско-преподавательским составом социогуманитарной кафедры в связи с введением в учебный процесс объединенной учебной дисциплины, в том числе проблемы, требующие незамедлительного решения. В статье отображен интегративный характер новой дисциплины, отмечены линии сопряженности социальной и культурной составляющей научного знания. Основной формой работы студенческой аудитории на практических занятиях выступает работа с первоисточниками, художественными текстами, которые подвергаются социологическому анализу и обработке. Авторы полагают, что в процессе освоения новой интегративной дисциплины «Социология и культурология» обучающиеся смогут ориентироваться в современной социокультурной ситуации, самостоятельно описывать и анализировать явления и процессы, происходящие в мировом сообществе. Авторы статьи делятся своими размышлениями по поводу включенности интегрированной дисциплины в диалогическую концепцию социогуманитарного знания, считая, что центре предмета «Социология и культурология» находится диалог, актуализируемый в текстовом пространстве. Оптимизация мыследеятельности субъекта посредством диалога, по мнению авторов, способствует формированию гармоничной личности с выработкой гражданской позиции, понимания исторической и социальной обусловленности деятельности индивида
UDC 316.74

Sociological Sciences

\section{THE SUBJECT OF SOCIOLOGY AND CULTUROLOGY IN THE ASPECT OF INTEGRATION OF THE SOCIAL AND HUMANITARIAN KNOWLEDGE: THEORETICAL AND METHODOLOGICAL APPROACH}

\author{
Volkova Polina Stanislavovna \\ Doctor of Philosophical Sciences, Professor \\ Perederiy Veronika Anatolievna \\ Candidate of Sociological Sciences, Associate \\ Professor \\ «Kuban State Agrarian University named after I.T. \\ Trubilin», Krasnodar, Russia \\ e-mail: sociolog@kubsau.ru
}

This article is devoted to the methodology of the research of the new of the academic discipline "Sociology and Culturology" for «Kuban State Agrarian University named after I.T. Trubilin». The article describes the specific tasks posed by the teaching staff of the social and humanitarian department in the connection with the introduction of the integrated academic discipline into the educational process, including problems that require immediate of the resolution. The article reflects the integrative character of the new discipline, the lines of conjugation of the social and cultural components of the scientific knowledge. The main form of the work of the student audience on the practical training is the working with the primary sources, literary texts, which are subjected to the sociological analysis. The authors suggest, that in the process of the development of the new integrative discipline "Sociology and Culturology» students will be able to navigate in the contemporary socio-cultural situation, self-describe and analyze the processes of the world community. The authors of this article share their thoughts on the inclusion of an integrated discipline in the dialogical concept of social and humanitarian of the knowledge, believing that the focus of the subject "Sociology and Culturology" is a dialogue that is actualized in the text. The optimization of the subject's thinking activity through of the dialogue, according to the authors, contributes to the formation of a harmonious personality with the development of a civic position, an understanding of the historical and social conditioning of the individual's activities 
Ключевые слова: КУЛЬТУРОЛОГИЯ,

МЫШЛЕНИЕ, ОБРАЗОВАНИЕ, РЕФЛЕКСИЯ,

СМЫСЛ, СОЦИОЛОГИЯ, ХУДОЖЕСТВЕННЫЙ

TEKCT

Doi: 10.21515/1990-4665-134-007
Keywords: CULTUROLOGY, INTELLECTION, EDUCATION, REFLECTION, MEANING, SOCIOLOGY, ARTISTIC TEXT

2015-2016 учебный год в стенах одного из старейших вузов Кубани и Северного Кавказа - Кубанского государственного аграрного университета им. И.Т. Трубилина был отмечен введением новой дисциплины «Социология и культурология». ФГБОУ ВО «Кубанский государственный аграрный университет имени И.Т. Трубилина» (КубГАУ) был открыт в невероятно сложной для России социокультурной ситуации в первый месяц лета 1918 года. На сегодняшний день КубГАУ представляет собой оснащенный всем необходимым для получения качественного образования и комфортного проживания студенческий комплекс, которым руководит доктор экономических наук, профессор А.И. Трубилин. С одной стороны, подобный опыт вызван необходимостью корректировки учебных планов в соответствии с новыми стандартами - речь идет о планомерной перестройке российского образования, обусловленной Болонской конвенцией. С другой стороны, сложившаяся ситуации как нельзя более отвечает преодолению многознания, результатом которого становится фрагментарность получаемой студенческой молодежью информации, ее дискретный характер. Заостряя внимание на осколочности знаний, из которых складывается картина мира современного поколения, А. Моль еще в конце прошлого века говорил о так называемой «мозаичной культуре» - определяющим мышление наших сограждан факторе [9]. При этом само понятие «мозаичная культура» указывает на явное противоречие двух его составляющих лексем. Речь идет об особенном сочетании слов, которое в лингвистике связывается с оксюмороном как соединением несоединимого по типу «красные чернила», «умный дурак» и т.п. 
Намеренное противоречие, заложенное во введенное в научный оборот А. Молем понятие, заключается в том, что культура исключает какую бы то ни было мозаичность. Ее имманентным свойством оказывается, в первую очередь, связь всего со всем. Отдавая себе отчет в том, что данная трактовка культуры менее всего отвечает наукообразным формулировкам, раскрывающим суть интересующего нас феномена, сошлемся на авторитет Ю. Арабова - прозаика, сценариста, поэта, работающего в тандеме с таким мастером отечественного кинематографа, как А. Сокуров (результатом их совместного творчества стали одиннадцать кинолент, в числе которых «Молох», 1999; «Телец», 2000; «Солнце», 2004; «Фауст», 2011). Общаясь со своими почитателями в рамках программы «Линия жизни», трансляция которой по каналу «Культура» проходила в начале февраля 2016 года, Ю. Арабов высказал, на первый взгляд, весьма крамольную мысль: «Мона Лиза» Л. да Винчи, равно как и любые другие, отсылающие нас к той или иной эпохе культурные знаки, которые «пошли в народ» в виде товарного бренда, декора пластикового пакета, рисунка на футболке и т.п. - это своего рода «консервы». Вызванное таким заявлением недоумение зрительской аудитории Ю. Арабов попытался разрешить следующим образом. Если человек не знает, кто такая «Джоконда», то это не значит, что такой человек бескультурен. Аналогичным образом знание о существовании какого-либо шедевра не делает человека по-настоящему культурным.

Солидаризируясь с нашим соотечественником, оговорим, что подлинная образованность складывается не столько из разрозненных сведений, почерпнутых из самых разных областей человеческой жизнедеятельности, сколько через осознание того, что «все в жизни цепью связано нетленной, все включено в один круговорот» (Л. Куклин). Другими словами, культура - это, прежде всего, образ мыслей. При этом качество такого образа напрямую зависит от уровня мышления или, что то же - культуры мышления того субъекта, в голове которого этот образ формируется. Не- 
случайно поэтому герой романа М.А. Булгакова «Собачье сердце» профессор Преображенский в ответ на сетование своего коллеги по поводу царящей повсеместно разрухи отвечал: «Что такое ваша разруха? Старуха с клюкой? Ведьма, которая выбила все стекла, потушила все лампы? Следовательно, разруха не в клозетах, она в головах...» [4, С. 346]. В данном контексте становится очевидным следующее: в своем высшем предназначении культура способствует формированию мышления, что с наибольшей полнотой отвечает названию дисциплины «Культурология» как Логоса (смысла) культуры. Соответственно, по аналогии с «Культурологией», «Социология» есть не что иное, как Логос (смысл) социума. В итоге в самом упрощенном виде интеграция культурологии и социологии должна подвести обучающуюся молодежь к необходимости разобраться в том, кто такой «Я», кто такой «не Я» (т.е. «Другой»), и кто такие «Мы»?

Поскольку вовлечение в пространство предмета «Социология и культурология» и оппозиций «Я - Другой», «Я - Мы» со всей очевидностью демонстрируют включенность интересующей нас интегрированной дисциплины в диалогическую концепцию гуманитарного знания, то ведущим методом работы со студенческой молодежью становится метод понимания. Подчеркнем, что в равной степени диалогической концепции гуманитарного знания отвечают и такие, изучаемые в КубГАУ учебные дисциплины, как «Логика», «Философия», «Риторика», «Русский язык». Речь в данном случае идет лишь о том, что на сегодняшний день предметникгуманитарий стоит перед необходимостью коррелировать свои действия с действиями коллег, акцентируя внимание на междисциплинарном характере отношений включенных в гуманитарный блок предметов. В данном контексте новая учебная дисциплина «Социология и культурология» первый шаг в этом направлении.

Будучи неотъемлемой составляющей всякого диалога как опыта согласования противоречий, понимание отличается от метода объяснения 
тем, что оно всегда личностно окрашено. Другими словами, если в результате объяснения студент овладевает знанием, которое носит нейтральный характер, то понимание отмечено рождением личностного смысла. Помимо этого, понимание рождается, как правило, только в ситуации непонимания, поскольку мыслить человек начинает только тогда, когда у него появляется потребность что-нибудь понять [11]. Принципиальное несовпадение объяснения и понимания опознается в разности задач, которые ставит перед сознанием А.Н. Леонтьев.

Первая задача состоит в необходимости осуществлять себя как познающее сознание. Процесс этот может протекать либо в сторону усвоения новых значений, либо - в сторону использования значений прежних. По сути, речь в данном случае идет о расширении кругозора участника диалогического общения, увеличения его словарного запаса посредством объяснение ранее неизвестного материала. Другую задачу А.Н. Леонтьев называет «задачей на смысл», предлагая решать ее в два действия: 1) открытие «значения для меня»; 2) выражение этого открытого «для меня» значения [8]. Подобный опыт оказывается возможным только посредством метода понимания. При этом именно текст культуры выступает полем методологических операций, обеспечивающих успешное решение каждого из действий.

Являя собой «воспроизводимую последовательность значимых элементов», в которой «реальность представлена и сконцентрирована в доступной пониманию форме», такой текст выступает в качестве «смыкающего компонента акта коммуникации» [3, С. 10], обуславливая переход от «равнодушного значения» как внешнего, нейтрального по отношению к субъекту знания, к исполненному внутреннего смысла «значению для меня». Знаменательно, что успешность подобного перехода обеспечивает метод интерпретации. Речь в данном случае идет об «осознанной рефлексии над опытом уже достигнутого понимания» или, что то же - о «способности 
понимать свое понимание» [2]. Другими словами, рассматриваемая с позиции высказанной рефлексии интерпретация предполагает:

- осознание своего понимания;

- приобщение к своему пониманию другого;

- построение системы аргументации, убеждающей в верности, т.е. культурности такого понимания в противоположность пониманию псевдокультурному.

Специально заметим, что в рамках интерпретативной стратегии, реализуемой в художественном творчестве, мы имеем дело с вторичной, относительно самостоятельной художественной деятельностью, в результате которой текст культуры сохраняется на уровне системы [7]. Примером художественной интерпретации может быть экранизация литературного текста («Дворянское гнездо» А. Кончаловского по роману И.А. Тургенева), визуализация музыкального пространства (хореография М. Бежара на музыку «Болеро» М. Равеля) и т.д.

В противоположность художественной интерпретации, реинтерпретация позиционируется как первичная, самостоятельная художественная деятельность, в процессе которой первоисточник сохраняется лишь на уровне элемента новой системы [5]. Имеется в виду тотальное переосмысление базового текста как намеренная художественная провокация. Примером реинтерпретации будет трилогия К. Муратовой «Котельная № 6», «Офелия», «Девочка и смерть», обращающая нашу память к «Палате № 6» А.П. Чехова, к трагедии У. Шекспира «Гамлет, принц Датский», к поэме А. Горького «Девушка и смерть». Другой пример - «Лунная соната» московского композитора В. Екимовского, в которой угадывается «эхо» «Лунной сонаты» Л. ван Бетховена и т.п. Значимость данной стратегии в контексте интересующей нас интегрированной дисциплины обусловлена следующим. Опыт реинтерпретации раздвигает пространство диалога, участниками которого становятся, как минимум, три субъекта: автор первоис- 
точника, автор нового художественного целого и вступающий в диалог как с классическим образцом, так и с современным его «прочтением» субъект восприятия. Соответственно, аналогично интерпретация, реинтерпретация также реализуется в рамках диалогической концепции гуманитарного знания, обуславливая равноправие всех участников диалогической ситуации, вследствие чего интертекстуальность трансформируется в интерсубъективность.

Несмотря на то, что как в случае интерпретации, так и реинтерпретации текста культуры результативность «диалога сознаний» (М. Бахтин) тем выше, чем большее количество связей учитывается в процессе его (текста) осмысления, методологические и методические подходы, объективность и субъективность научных принципов, лежащих в основе культурологического и социологического знания являются различными. В частности, «контент-анализ» в социологии соотносится со строго вымеренной процедурой измерения, выступая в качестве «анализа содержания» самых разных, в том числе и художественных, текстов. Тем не менее, подсчет суждений, требования репрезентативности, фиксация материалов в тексте, статистическое описание, получение конкретных цифр (количественные показатели) дополняются социокультурными аспектами, реализуемыми сквозь призму аксиологии, вбирающими в себя персонизированные чувства исследователя к персонажу/герою, его личное отношение к прочитанному, услышанному или увиденному (качественные показатели).

Другими словами, подвергая социологическому анализу источники информации, которые одновременно затрагивают индивидуальный опыт и поведение индивида как личности и как участника социальной жизни [10, С.64-65], социолог-исследователь выясняет, что представляет текст в своей сущностной характеристике, тем самым оценивая и моделируя социальную действительность. В этом и проявляется специфичность социологического анализа текста культуры. Однако гуманистический взгляд на изуча- 
емый текст в полной мере сближают эти, на первый взгляд, антиномичные позиции, предоставляя тем самым возможность нахождения определенного компромисса между разнородными научными дисциплинами, обеспечивая гармоничное взаимодействие познающего и смыслообразующего типов познания в процессе мыследеятельности субъекта. Важность и непреходящая ценность подобного опыта обусловлена тем, что “три области человеческой культуры - наука, искусство и жизнь - обретают единство только в личности, которая приобщает их к своему единству” [1,С. 7].

Тот факт, что искомая связь нередко становится чисто механической, внешней, напрямую связан с ситуацией, когда и педагог, и студент в процессе своего взаимодействия делают ставку исключительно на деятельностью познающего сознания. Принимая во внимание обстоятельство, согласно которому такая деятельность, как правило, коррелирует с развитием коммуникативных способностей, необходимо отдавать себе отчет в следующем. Для большинства россиян способность говорить не связывается с понятием речевой собственности, отмеченной уникальностью и неповторимостью личности говорящего. Более того, современная социокультурная ситуация отмечена тотальной девальвацией слова, которое уподобилось расхожей монете. Именно поэтому мы не только не напрягаемся до речи, но, напротив, с готовностью пользуемся тем, что можно отнести к словесной шелухе.

Напротив, актуализация личностного смысла, который изначально переживается исключительно на уровне чувства, требует серьезной внутренней работы. Такой опыт можно сравнить с ситуацией, когда слушатель стоит перед необходимостью передать свое впечатление от звучащей музыки в беседе с таким же, как он, меломаном. Поскольку каждый переживает общение с прекрасным по-своему, высказать свои впечатления так, чтобы приобщить к богатству своего видения или слышания кого-либо другого, не опускаясь при этом до банальности, отказываясь от культур- 
ных штампов и клише, не так-то просто. Причем, в обыденной жизни, наполненной повседневной суетой, наши откровения, как правило, мало кого интересуют, разве что состояние влюбленности заставляет нас мучительно подыскивать слова, чтобы поведать о своем чувстве так, как никто прежде не говорил! Однако, помня о том, что без выражения открытого «для меня» значения «задача на смысл» так и не будет решена, ни при каких обстоятельствах нельзя довольствоваться лишь тем, что известно «с чужих слов».

Соответственно, отвечая на поставленный в тексте вопрос, как пишет В. Виноградов, «художественное произведение задано читателю не как система положительного содержания, а скорее как известная схема и загадка, которую читатель должен еще дополнить и разгадать в конкретносмысловом плане» [6,С.9]. Каждый из нас решает свою собственную «задачу на смысл», что делает верным следующее наблюдение: преодолеть механичность внешних связей и отношений можно только тогда, когда я готов отвечать за все, что вовлекается в орбиту моей личности. «За то, что я пережил и понял.,, - пишет М.М. Бахтин, - я должен отвечать своею жизнью, чтобы все пережитое и понятое не осталось бездейственным в ней... Личность должна стать сплошь ответственной: все ее моменты должны не только укладываться рядом во временном ряду ее жизни, но проникать друг в друга». [1,С. 7].

В связи с тем, что опыт интеграции предмета «Социология и культурология» носит экспериментальный (разведывательный) характер, вполне ожидаемыми становятся проблемы, к числу которых можно отнести:

- отсутствие опыта в преподавании данной дисциплины, которая помимо профессиональной компетентности профессорскопреподавательского состава требует и особого педагогического мастерства; 
- минимизация объема лекционного материала при содержательной насыщенности нового учебного курса;

- поиск новых способов закрепления и систематизации знаний молодого поколения россиян в области социокультурных проблематики;

- выявление точек соприкосновения при осмыслении ключевых сторон культурологической или социологической мысли в сжатом формате.

Преодоление имеющихся на сегодняшний день затруднений позволит посредством нового предмета «Социология и культурология» заложить фундамент для становления личности гражданина России, обладающего чувством патриотизма и любви к своему Отечеству.

\section{Список литературы}

1. Бахтин, М.М. Искусство и ответственность / М.М. Бахтин. Работы 1920-х годов. Киев: Next, 1994. - С. 7-8.

2. Богин, Г.А. Методологическое пособие по интерпретации художественного текста (для занимающихся филологией иностранцев). Режим доступа: http:// window.edu.ru,>resource/096/42096///bogin_glava4.htm

3. Брудный А. А. Психологическая герменевтика / А. А. Брудный. - Москва: Лабиринт, 2005. - $336 \mathrm{c}$.

4. Булгаков, М.А. Собачье сердце / М. А. Булгаков Багровый остров: Ранняя сатирическая проза. - М.: Художественная литература, 1990. - С. 321-412.

5. Волкова, П.С. Реинтерпретация художественного текста (на материале искусства ХХ века): моногр. / П. С. Волкова. - Краснодар: ООО Издательский дом “ХОРС”, 2008. $-200 \mathrm{c}$.

6. Виноградов В.В. О теории художественной речи. / В.В. Виноградов. - М.: Высшая школа, 1971. - 240 с.

7. Гуренко, Е. Г. Проблемы художественной интерпретации: (Философский анализ) / Е. Г. Гуренко. - Новосибирск: Наука, 1982. - 256 с.

8. Леонтьев, А.Н. Избранные психологические произведения: В двух томах. /А.Н. Леонтьев. - М.: Педагогика, 1983. - 370 с.

9. Моль, А. Социодинамика культуры. / А. Моль. - М: ЛКИ, 2008. - 416 с.

10. Передерий, В.А. Технологии исследований социальной жизни: учеб. пособие / В.А. Передерий. - Краснодар: КубГАУ, 2012. - 129 с.

11. Рубинштейн, С. Л. Основы общей психологии. / С.Л. Рубинштейн. - СПб.: Издательство “Питер”, 2000. - 712 с.

\section{References}

1.Bahtin, M.M. Iskusstvo i otvetstvennost' / M.M. Bahtin. Raboty 1920-h godov. Kiev: Next, 1994. - S. 7-8.

2. Bogin, G.A. Metodologicheskoe posobie po interpretacii hudozhestvennogo teksta (dlja zanimajushhihsja filologiej inostrancev). Rezhim dostupa: http:// window.edu.ru,>resource/096/42096///bogin_glava4.htm 
3. Brudnyj A. A. Psihologicheskaja germenevtika / A. A. Brudnyj. - Moskva: Labirint, 2005. - $336 \mathrm{~s}$.

4. Bulgakov, M.A. Sobach'e serdce / M. A. Bulgakov Bagrovyj ostrov: Rannjaja satiricheskaja proza. - M.: Hudozhestvennaja literatura, 1990. - S. 321-412.

5. Volkova, P.S. Reinterpretacija hudozhestvennogo teksta (na materiale iskusstva $\mathrm{HH}$ veka): monogr. / P. S. Volkova. - Krasnodar: OOO Izdatel'skij dom "HORS", 2008. - 200 c.

6. Vinogradov V.V. O teorii hudozhestvennoj rechi. / V.V. Vinogradov. - M.: Vysshaja shkola, 1971. - $240 \mathrm{~s}$.

7. Gurenko, E. G. Problemy hudozhestvennoj interpretacii: (Filosofskij analiz) / E. G. Gurenko. - Novosibirsk: Nauka, 1982. - 256 s.

8. Leont'ev, A.N. Izbrannye psihologicheskie proizvedenija: V dvuh tomah. /A.N. Leont'ev. - M.: Pedagogika, 1983. - 370 s.

9. Mol', A. Sociodinamika kul'tury / A. Mol'. - M: LKI, 2008. - 416 s.

10. Perederij, V.A. Tehnologii issledovanij social'noj zhizni: ucheb. posobie / V.A. Perederij. - Krasnodar: KubGAU, 2012. - 129 s.

11. Rubinshtejn, S. L. Osnovy obshhej psihologii. / S.L. Rubinshtejn. - SPb.: Izdatel'stvo "Piter", 2000. - 712 s. 